\title{
TRADUÇÃO DO CONTO ATRAVESSANDO A NEVE, \\ DE MIYAZAWA KENJI: ALGUNS ASPECTOS
}

Márcia Hitomi Takabashi ${ }^{7}$

RESUMO: Neste trabalho apresentamos uma tradução para o Português do conto Yuki watari ("Atravessando a neve"), de Miyazawa Kenji, e discutimos alguns aspectos do processo tradutório, baseando-nos em perspectivas teóricas. Focalizamos, em especial, as dificuldades em se traduzir aspectos peculiares a uma cultura diversa, e sugerimos algumas possibilidades de resolvê-las.

Palavras-chave: Miyazawa Kenji; tradução; onomatopéia; cultura; double bind

ABSTRACT: In this paper we present a translation to Portuguese of the tale Yuki watari ("Crossing the snow"), by Miyazawa Kenji, and we discuss about some aspects of the translation process, based on theoretical perspectives. We focus in special the difficulties in translating peculiar elements to another culture, and suggest some possibilities to solve them.

Key words: Miyazawa Kenji; translation; onomatopoeia; culture; double bind

\section{PARTE UM: \\ O filhotede raposa, Konzaburô}

A neve, que havia congelado completamente, estava agora mais sólida do que mármore, e mesmo o céu parecia feito de uma lâmina de pedra azul, gélida e lisa.

- Neve dura, kanko, neve gelada, shinko.

O sol queimava com sua pureza branca, e disseminava sobre a neve a fragrância dos lírios. Então, uma vez mais, reluziu sobre a neve, giragira.

1. doutoranda no curso de Teoria Literária e Literatura Comparada da FFLCH-USP. 
As árvores carregadas de geada faiscavam, pikapika, como se tivessem sido salpicadas com açúcar cristal.

- Neve dura, kanko, neve gelada, shinko.

Shiro e Kanko calçaram suas pequenas botas, yukigutsu ${ }^{2}$, e seguiram pela campina, kikku kikku kikku.

Haveria novamente um dia encantador como aquele? Hoje eles estavam livres para tomar qualquer direção que quisessem, mesmo por lugares por onde eles normalmente não poderiam passar, como campos de painço ou campinas cheias de grama. Tudo estava plano como uma simples lâmina, e a superfície inteira brilhava, kira kira kira kira, como se fosse feita de inúmeros espelhinhos.

- Neve dura, kanko, neve gelada, shinko.

As duas crianças chegaram à floresta. Um grande carvalho, como que afundando na neve, inclinava-se com o peso dos esplêndidos pingentes transparentes que pendiam de seus ramos.

Olhando para a floresta, as crianças gritaram:

- Neve dura, kanko, neve gelada, shinko. Raposinha, você quer uma noiva? Quer?

Por algum tempo, tudo ficou em silêncio. Justamente na hora em que as crianças tomaram fôlego, prontas para gritar novamente, um filhote de raposa branca surgiu de dentro da floresta, dizendo, "Neve gelada, shinshin, neve dura, kankan", enquanto caminhava pela neve, kishiri kishiri.

Tomado de surpresa, Shiro parou em frente a Kanko, como que querendo protegê-la, pisando firme e falando de volta:

- Raposa kon kon, raposa branca! Se você quer uma noiva, eu the darei uma.

Embora ainda fosse bastante pequena, a raposa torceu um de seus bigodes, agulha prateada, e respondeu:

- Shiro, shinko, Kanko, kanko. Não é uma noiva que eu quero.

Shiro riu, e continuou:

- Raposa kon kon, pequena raposa, se você não quer uma noiva, que tal algum mochi?

Então, balançando a cabeça duas ou três vezes, o filhote de raposa respondeu alegremente:

- Shiro, shinko, Kanko, kanko, poderia dar a vocês algum bolinho de painço? de Shiro:

Kanko achou a troca tão engraçada que começou a cantar, escondida atrás

- Raposa kon kon, pequena raposa, não serão os bolinhos da raposa cocô de coelho?

A raposinha branca, Konzaburo, riu e explicou:

2. Botas para andar na neve, feitas de palha de arroz trançada

3. Bolinho de arroz 
- Não, de jeito algum. Pessoas especiais como vocês comeriam algo como bolinho marrom de coelho? Até hoje dizem que enganamos e pregamos peças, mas digo que nos acusam em falso.

- Então, é mentira que as raposas enganam? - perguntou Shiro, surpreso.

Konzaburo respondeu, honesto:

- Tudo mentira. A maior das mentiras. Os que dizem que foram enganados por nós são os que bebem muito, ou são medrosos. É bem interessante, sabe? Não muito tempo atrás, Jinbee-san sentou-se em frente à nossa casa em uma noite de lua, recitando um jôrurit Todos nós saímos e ficamos olhando.

- Se fosse Jinbee-san, não seria um jôruri o que estava recitando. Seria mais parecido com um naniwabushi ${ }^{5}$ - gritou Shiro.

Isso pareceu fazer sentido a Konzaburo:

- Talvez seja isso. De qualquer forma, por favor, peguem algum bolinho. Para oferecê-los a vocês preparei o campo, semeei a semente, carpi a terra, soquei os grãos para virar farinha, sovei, assei e cobri com açúcar. Que tal? Gostaria de oferecer um prato cheio.

Shiro riu:

- Senhor Konzaburo. Nós comemos alguns mochi antes de vir para cá, não estamos com fome. Você poderia nos convidar novamente, outro dia?

A raposinha Konzaburo bateu suas patas curtas, alegre, batabata:

- Está bem assim? Bem, vou oferecê-los a vocês quando tivermos a nossa festa da lanterna mágica. Por favor, venham sem falta. Será na próxima noite de lua, quando a neve virar gelo. A festa começa às oito, então deixe-me dar a vocês alguma entrada. Quantas?

- Bem, cinco - disse Shiro.

- Cinco? São duas para você e sua irmã, mas para quem são as outras? perguntou Konzaburo.

- São para os meus irmãos mais velhos - respondeu Shiro.

- Seus irmãos não têm onze anos? - perguntou novamente Konzaburo.

- Não, o mais novo dos meus irmãos mais velhos está no quarto ano, então são oito mais quatro, o que dá doze anos - disse Shiro.

Konzaburo torceu novamente seu bigode, seguro de si:

- Bem, então, sinto muito, mas não poderemos convidar seus irmãos. Apenas vocês dois podem vir. Como vamos reservar um lugar especial para vocês, será muito interessante. O título do primeiro quadro é "Não se deve tomar saquê". Aqui vemos dois rapazes da vila de vocês, Taemon e Seisaku, atordoados de tanto saquê, quando

4. Peça musical cantada com acompanhamento do shamisen, instrumento musical japonês de três cordas. Começou a ser difundida no Japão em meados de 1400

5. Narrativas que se apresentavam sob as mais diversas formas, como peças teatrais, obras de arte e obras literárias, entre outras. Eram executadas com o acompanhamento do shamisen, por uma pessoa apenas. Começaram a ser difundidas ao final do século XIX, obtendo destaque no início do século XX 
iam comer alguns manjü $\hat{u}^{6}$ esquisitos e $s o b a^{7}$, aqui na campina. Eu também apareço no quadro. O título do segundo quadro é "Cuidado com as armadilhas" Ele mostra o nosso Konbee preso em uma armadilha, na campina. É um desenho mesmo. Não é fotografia. O título do terceiro quadro é "Não despreze o fogo" Mostra como nossa raposa Konsuke queimou seu rabo quando estava indo à casa de vocês. Por favor, venham.

Os dois concordaram, alegres.

A raposa torceu a boca de um jeito engraçado e começou a bater os pés kikku kikku ton ton kikku kikku ton ton, abanando o rabo e balançando a cabeça. Por um momento ficou pensativa, mas deve ter tido alguma idéia pois, subitamente, começou a cantar, marcando o ritmo com as patas:

- Neve gelada, shinko, neve dura, kanko,

Os manjû na campina são po po po.

Taemon, bêbado e cambaleante,

Ano passado comeu trinta e oito

Neve gelada, shinko, neve dura, kanko,

O soba na campina é ho ho ho.

Seisaku, bêbado e cambaleante,

Ano passado comeu treze tigelas.

Encantados com a apresentação da raposa, Shiro e Kanko começaram a dançar também.

Kikku, kikku, tonton. Kikku, kikku, tonton. Kikku, kikku, kikku, kikku, tontonton.

Shiro cantou:

- Raposa kon kon, pequeno filhote. Ano passado a raposa Konbee pôs sua pata esquerda na armadilha. Escute sua luta: konkon batabata konkonkon.

Kanko cantou:

- Raposa kon kon, pequeno filhote. Ano passado a raposa Konsuke teve a ponta do seu rabo em chamas quando tentava roubar um peixe grelhado. Ouça seu choro: kyan kyan kyan.

Kikku, kikku, tonton. Kikku, kikku, tonton. Kikku, kikku, kikku, kikkutontonton.

Enquanto os três iam dançando pelo caminho, foram entrando na floresta. Os botões de magnólia, vermelhos feito artesanato de cera, brilhavam ao sopro do vento, pikari pikari. Em meio à neve da floresta, as sombras azuis das árvores eram uma rede cobrindo o solo e, onde quer que a luz batesse, tinha-se a impressão de que desabrochavam os lírios prateados.

De repente, a raposa Konzaburo falou:

- Vamos convidar o filhote de corça também? Ele toca flauta muito bem.

Shiro e Kanko bateram palmas, felizes. Então, todos gritaram:

6. Bolinho com recheio de pasta doce de feijão.

7. Macarrão de trigo sarraceno. 
- Neve dura, kanko, neve gelada, shinko, a corça quer uma noiva, quer uma noiva.

Ao longe, uma voz doce e agradável respondeu:

- Vento do norte pii pii, vento do oeste dô dô.

A raposa Konzaburo olhou como se sentisse que a corça estava zombando dela, e falou, brusca:

- Era o filhote de corça. Ele é tão tímido que não vem até aqui. Vamos tentar gritar de novo?

Novamente os três gritaram:

- Neve dura, kanko, neve gelada, shinko, a corça quer uma noiva, quer uma noiva.

Então, de algum lugar distante - não se sabe se era o som do vento, ou o chamado da flauta, ou a canção da corça - veio a resposta:

- Vento do norte pii pii, kanko kanko

- Vento do oeste dô dô, dokko dokko."

A raposa torceu de novo o bigode e disse:

- Vocês vão se ver em apuros se a neve derreter; é melhor voltarem para casa. Por favor, venham novamente quando a neve congelar numa noite de lua. Nós mostraremos aqueles quadros.

- Neve dura, kanko, neve gelada, shinko - Shiro e Kanko atravessaram a neve de prata de volta para casa e, enquanto andavam, cantavam:

- Neve dura, kanko, neve gelada, shinko.

\section{PARTE DOIS}

\section{O festival da lanterna mágica da escola primária de raposas}

A grande lua cheia, branco-azulada, ergueu-se calmamente sobre o Monte Hinokami.

A neve brilhava azulada, chika chika, e naquele dia, também, congelara dura feito calcário cristalizado.

Shiro, pensando na promessa que fizera à raposa Konzaburo, falou baixinho à sua irmã, Kanko:

- Esta noite é o festival da lanterna mágica das raposas. Vamos?

Kanko, dando um salto no ar, gritou:

- Vamos! Vamos! Raposa kon kon, filhote de raposa. Kon kon, raposa Konzaburo.

Então, o segundo irmão, Jiro, disse:

- Vocês estão indo passear no local das raposas? Eu também quero ir.

Shiro deu de ombros e disse, perturbado: 
- Mas, irmão, o festival da lanterna mágica das raposas é só para quem tem até onze anos. Está escrito nos ingressos.

Jiro falou:

- O quê? Mostre-me! Ah, diz aqui: "Solicitamos que, à exceção dos pais e irmãos dos alunos da escola, visitantes com mais de doze anos não compareçam" Aquelas raposas são bem astutas. Então não posso ir, não tem jeito. Bem, se vocês dois estão indo, por que não levam algum mochi? Que tal estes kagami mochi ${ }^{\text {? }}$ ?

Shiro e Kanko calçaram seus pequenos yukigutsu e saíram, carregando os mochi.

Seus irmãos Ichiro, Jiro e Saburo, da porta de entrada, gritaram:

- Até logo! Se vocês encontrarem uma raposa adulta, fechem os olhos imediatamente. Que tal uma despedida? Neve dura, kanko, neve gelada, shinko, a raposinha quer uma noiva? Quer?

A lua estava alta no céu e a floresta, envolta por uma neblina branco-azulada. As duas crianças chegaram na floresta.

Ali estava um filhote de raposa pequeno e branco, trazendo no peito um distintivo de noz:

- Boa noite. Vocês chegaram cedo. Estão com os ingressos?

- Sim, estamos - eles os tiraram.

- Naquela direção, por favor - a raposa virou seu corpo e seus olhos cintilaram, pachi pachi, quando ela apontou com as patas o interior da floresta.

$\mathrm{Na}$ floresta, os raios de luar perfuravam o céu como lanças diagonais azulclaras. As duas crianças chegaram em uma clareira.

Viram muitas raposas estudantes que já haviam se juntado ali e jogavam cascas de castanhas umas nas outras, ou atracavam-se em luta. Era realmente engraçado um filhote de raposa muito, muito pequeno, não maior do que um rato, que subia nos ombros de um filhote de raposa maior e tentava pegar as estrelas.

Uma faixa branca estava pendurada em um galho de árvore diante de todos.

Subitamente, uma voz surgiu do fundo:

- Boa noite. Bem-vindos! Desculpem-me pelo outro dia.

Quando Shiro e Kanko, surpresos, viraram-se, perceberam que era Konzaburo.

Konzaburo vestia uma esplêndida casaca, com uma flor de narciso presa à lapela. Ele limpou sua boca pontuda com um lenço branco.

Shiro fez uma pequena reverência e disse:

- Por favor, desculpe-nos pelo outro dia. E muito obrigado por esta noite. Por favor, divida este mochi com todos.

Todas as raposas estudantes olhavam para o lado onde estavam.

Konzaburo estufou e peito e aceitou os mochi:

8. Bolinho de arroz redondo oferecido aos deuses no Ano Novo 
- Desculpe-nos pelo incômodo de terem trazido este presente. Por favor, acomodem-se. $\mathrm{O}$ festival logo vai começar. Com licença.

Konzaburo afastou-se, levando os mochi.

As raposas estudantes gritaram:

- Neve dura, kanko, neve gelada, shinko, mochi duros são kattarako, mochi brancos são bettarako.

Ao lado da cortina apareceu um grande cartaz, onde se lia "Uma doação de muito mochi foi feita pelo humano Shiro e pela humana Kanko" As raposas estudantes bateram palmas alegres, pachi pachi.

Nesse momento um apito soou, pii.

Limpando a garganta, ehen ehen, Konzaburo apareceu, saindo do lado da cortina, e curvou-se respeitosamente. Todos fizeram silêncio.

- Temos hoje uma linda noite. A lua parece um prato de pérola. As estrelas parecem orvalho congelado em nossa campina, kira kira. Bem, o festival da lanterna mágica vai começar. Espero que vocês olhem à frente, com toda atenção, sem piscar seus olhos ou espirrar. Nesta noite, temos dois convidados respeitáveis, então vocês devem ficar todos muito quietos. Em hipótese alguma vocês podem jogar cascas de castanhas para o lado deles. Vamos começar.

Todos bateram palmas alegres, pachi pachi. Então Shiro disse baixinho a Kanko:

- Konzaburo fala muito bem!

Um apito soou, pii.

Grandes letras surgiram na cortina: "Não se pode tomar saquê" Então as letras desapareceram, e uma foto tomou seu lugar. Era a cena de um velho bêbado, segurando um objeto estranho e redondo.

Todos bateram os pés e cantaram.

Kikkukikkutontonkikkukikkutonton

- Neve gelada, shinko, neve dura, kanko

Os manjû na campina são po po po.

- Taemon, bêbado e cambaleante,

- Ano passado comeu trinta e oito.

Kikkukikkukikkukikkutontonton

A imagem se esvaiu. Shiro disse baixinho a Kanko:

- Aquela era a canção de Konzaburo.

Outra fotografia apareceu. Um jovem bêbado estava com o rosto como que enfiado em uma tigela de magnólia, comendo algo. Konzaburo, vestido de branco, observava a cena de uma certa distância.

Todos bateram os pés e cantaram.

Kikkukikkutonton, kikkukikku, tonton

- Neve gelada, shinko, neve dura, kanko,

O soba na campina é ho ho ho. 
Seisaku, bêbado e cambaleante,

Ano passado comeu treze tigelas.

Kikku, kikku, kikku, kikku, ton, ton, ton.

A fotografia esvaiu-se, e houve um rápido intervalo.

Uma graciosa raposa fêmea trouxe para as duas crianças uma bandeja com bolinhos de painço.

Shiro, subitamente, ficou sem saber o que fazer, pois acabara de ver Taemon e Seisaku comendo algo ruim, não conscientes do que seria aquilo.

Todas as raposas estudantes ficaram olhando, dizendo umas às outras em voz baixa, "Será que vão comer? Será que vão comer?" Kanko ficou embaraçada, sentindo seu rosto ruborizar-se, com o prato na mão. Então, Shiro convenceu-a, dizendo:

- Vamos comer. Coma um. Eu não acredito que Konzaburo queira nos trapacear.

As crianças comeram todos os bolinhos. Como estavam deliciosos! As raposas estudantes ficaram tão felizes que pularam e dançaram.

Kikkukikkutonton, kikkukikkutonton.

- O sol brilha o dia todo, kankan,

A lua brilha a noite toda, tsuntsun,

Mesmo que tivessem seus corpos dilacerados,

As raposas estudantes não mentiriam.

Kikku, kikkutonton, kikkukikkutonton.

- O sol brilha o dia todo, kankan,

A lua brilha a noite toda, tsuntsun,

Mesmo que caíssem e se congelassem,

As raposas estudantes não roubariam.

Kikkukikkutonton, kikkukikkutonton.

- O sol brilha o dia todo, kankan,

A lua brilha a noite toda, tsuntsun,

Mesmo que seus corpos fossem rasgados em pedaços,

As raposas estudantes não invejariam o próximo.

Kikkukikkutonton, kikkukikkutonton.

Shiro e Kanko choraram de alegria.

Um apito soou, pii.

Grandes letras refletiram na tela: "Cuidado com as armadilhas" Então as letras se apagaram e foram substituídas por um quadro. Era uma cena da raposa Konbee com sua perna esquerda presa em uma armadilha. Todos cantaram:

- Raposa kon kon, filhote de raposa, ano passado a raposa Konbee teve sua perna esquerda presa em uma armadilha: konkonbatabata konkonkon.

Shiro disse baixinho a Kanko:

- Ei, é a canção que eu fiz! 
Quando o quadro se apagou, a frase "Não despreze o fogo" apareceu. Ela também se esvaiu, e foi substituída por um quadro. Ele mostrava o momento em que a raposa Konsuke estava para roubar um peixe grelhado e seu rabo pegou fogo.

Todas as raposas estudantes gritaram:

- Raposa kon kon, filhote de raposa. Ano passado a raposa Konsuke teve a ponta de seu rabo incendiada quando tentava roubar um peixe grelhado: kyan kyan kyan.

Um apito soou, pii, e o quadro iluminou-se. Konzaburo apareceu novamente e disse:

- Senhores, é o final do espetáculo desta noite. Hoje aconteceu algo que vocês não devem esquecer. Crianças humanas, inteligentes, que não estavam um pouco sequer bêbadas, aceitaram nossa comida e comeram-na. Então, de agora em diante, mesmo quando tornarem-se adultas, vocês não deverão mentir, nem invejar as pessoas. Se forem bem-sucedidos, vocês serão capazes de apagar a má reputação que nós raposas temos até agora. Isto conclui o nosso encontro.

As raposas estudantes ficaram emocionadas. Algumas acenavam no ar, e outras ficaram em pé, para expressar sua concordância. Lágrimas fluíram de seus olhos, kira kira.

Konzaburo pôs-se diante das duas crianças, curvando-se polidamente, e falou:

- Bem, então, adeus. Nós não nos esqueceremos da gentileza que tiveram para conosco esta noite.

As crianças curvaram-se, dizendo adeus, e tomaram o caminho de casa. As raposas estudantes correram atrás delas, e encheram as dobras e mangas de seus quimonos com nozes, castanhas, pedras salpicadas de azul, e coisas semelhantes, dizendo: "Isto aqui é para vocês", ou "Por favor, levem isto" Elas voltaram e desapareceram como o vento.

Konzaburo riu enquanto os observava.

As crianças deixaram a floresta e cruzaram a campina.

Elas viram três sombras negras ao cruzarem a campina, vindo em direção a elas. Seus irmãos mais velhos tinham vindo buscá-las.

O conto Atravessando a neve é de autoria de Miyazawa Kenji (1896-1933), que nasceu e viveu na província de Iwate, norte do Japão. É um dos escritores mais conhecidos da literatura infanto-juvenil japonesa, embora sua vasta obra só tenha sido reconhecida postumamente.

Kenji nasceu em uma família abastada: seu pai era proprietário de terras e comerciante, possuindo uma loja de roupas usadas e uma casa de penhores. No entanto, seus vizinhos, na sua grande maioria lavradores pobres ou carvoeiros, mal 
tinham como sustentar suas famílias na região inóspita onde viviam, com inverno rigoroso e chuvas intensas durante o verão. Penalizado com a situação de miséria que os rodeava, Kenji preocupou-se durante toda sua vida em ajudá-los, tendo inclusive se formado em Agronomia com essa finalidade: ensinava aos lavradores como fabricar diferentes tipos de fertilizantes, sugeria novas sementes de variedades vegetais. Lecionou também em uma escola superior de agricultura. E, com suas crenças budistas, aplicava preceitos religiosos em seus ensinamentos, que procuravam harmonizar o homem aos elementos da natureza. Assim, podemos observar na obra de Kenji descrições paisagísticas do local onde viveu, assim como elementos religiosos, como a salvação pessoal e a busca da felicidade.

A tradução do conto do Japonês para o Português foi feita de maneira quase literal, no intuito de se ter uma melhor idéia acerca do original. Através de sua leitura, é possível sentir a presença de elementos de uma outra cultura, diversos aos de nossa vivência. W.Humboldt, como SELIGMANN-SILVA (2005:170) cita em sua obra, percebia cada língua como uma leitura, uma interpretação, vale dizer: uma construção do mundo. Também para PAZ (1990:12), cada língua é uma visão de mundo, cada civilização é um mundo. De fato, quando lemos o texto de $\mathrm{Kenji}$, as descrições paisagísticas e o fluxo das onomatopéias "invadem" nossos sentidos, dando-nos a impressão de estarmos diante de um outro mundo. No entanto, por estarmos tratando de tradução de textos, não se pode esquecer que a tradução implica uma transformação do original, como mencionou PAZ (1990:14): "o texto original jamais reaparece em outra língua; não obstante, está presente sempre porque a tradução, sem dizê-lo, menciona-o constantemente ou converte-o em um objeto verbal que, ainda que distinto, o reproduz"

Na tradução, quando se privilegia a língua 1, surgem elementos de estranheza à língua 2. Segundo o texto de BERNARDINI (2006:60), "quando se trata de "render" o estilo, a ambiência, o tom, o ritmo, o léxico, a "cultura" da língua 1 (que é o que ECO (1995: 122-123) expõe em "Semiótica da fidelidade"), então o tradutor, para transpor os elementos da língua 1 para a língua 2, dando ênfase ao espírito da língua 1 , em todas as possíveis modalidades, deve ser excelente nas duas línguas, ou trabalhar em conjunto com um outro tradutor (nativo) que o supra de quanto não tem, no que se refere à língua 1" Para SELIGMANN-SILVA (2005), a tradução implica grande perda do mundo original sendo, assim, necessário incorporar o espírito do autor - o abandono. É necessário estudar o autor antes da tradução. Ainda, OTTONI (2005:120-121) comenta que, para traduzir o sentido, não basta somente conhecer as palavras, é necessário conhecer as coisas a que 0 texto se refere; isto é, não é suficiente exigir do tradutor somente o conhecimento da língua estrangeira, mas também é necessário exigir o conhecimento do "sentido e da matéria" da obra a ser traduzida.

Assim, no processo de tradução do conto Atravessando a neve, surgem algumas dificuldades relacionadas aos aspectos mencionados. Em primeiro 
lugar, a questão das onomatopéias, constantes no texto de Kenji. Seria possível, a um leitor que desconheça o Japonês, entender seu efeito, sem a explicação correspondente?

No caso de um tradutor que não tenha o Japonês como língua materna, um procedimento adequado seja talvez solicitar a um falante nativo da língua explicações acerca do sentido das diversas onomatopéias que surgem ao longo do conto. É interessante notar que, para um leitor japonês, o texto perde o seu efeito com a sua ausência, ao passo que, para um leitor que adquiriu posteriormente a língua, isso não acontece com tanta intensidade.

No Japonês, existem duas categorias de onomatopéias:

- giseigo: onomatopéias que representam o som;

gitaigo: onomatopéias consideradas sensoriais, ou visuais, relacionadas às imagens.

Segundo CHANG (2000:v), o papel de tal simbolismo sonoro é muito importante porque o Japonês contém um número de verbos muito limitado. Um dos papéis da mimese e da onomatopéia, portanto, é preencher o lapso e fornecer meios para uma expressão concisa quando um verbo suficientemente descritivo não existe. Elas tornam a linguagem vívida.

No texto, há várias onomatopéias semelhantes, utilizadas para um mesmo verbo, distribuídas como no quadro que se segue:

\begin{tabular}{|l|l|l|}
\hline \multicolumn{1}{|c|}{ Onomatopéia } & \multicolumn{1}{|c|}{ Significado } & \multicolumn{1}{c|}{ Contexto } \\
\hline $\begin{array}{l}\text { 1. giragira } \\
\text { 2. pikapika }\end{array}$ & $\begin{array}{l}\text { 1. gitaigo do verbo "reluzir" } \\
\text { 2. gitaigo do verbo "cintilar" }\end{array}$ & $\begin{array}{l}\text { 1. brilho do sol } \\
\text { 2. remete a uma imagem de } \\
\text { brilho mais suave do que } \\
\text { giragira }\end{array}$ \\
3. kira kira & 3. gitaigo do verbo "reluzir" & $\begin{array}{l}\text { 3. remete a uma imagem de } \\
\text { brilho intenso, contínuo }\end{array}$ \\
4. phiki pikari & 4. gitaigo do verbo "brilhar" & $\begin{array}{l}\text { 4. imagem de brilho } \\
\text { instantâneo, como um facho } \\
\text { de luz; também descreve } \\
\text { algo que brilha em intervalos } \\
\text { regulares }\end{array}$ \\
6. pachi pachi & $\begin{array}{l}\text { 5. gitaigo do verbo "piscar" } \\
\text { (no texto surge como do verbo "piscar" } \\
\text { "cintilar") }\end{array}$ & $\begin{array}{l}\text { 5. indica algo que brilha mas } \\
\text { quirritante aos olhos olhos }\end{array}$ \\
\hline $\begin{array}{l}\text { 1. kikku kikku } \\
\text { 2. kishiri kishiri }\end{array}$ & $\begin{array}{l}\text { 1. giseigo do verbo "andar" } \\
\text { 2. giseigo do verbo "andar" }\end{array}$ & $\begin{array}{l}\text { 1. passos rápidos } \\
\text { 2. passos alongados, arrastados }\end{array}$ \\
\hline $\begin{array}{l}\text { 1. bata bata } \\
\text { 2. pachi pachi }\end{array}$ & $\begin{array}{l}\text { 1. giseigo do verbo "bater" } \\
\text { 2. giseigo do verbo "bater" }\end{array}$ & $\begin{array}{l}\text { 1. batidas com mãos e pés } \\
\text { 2. bater palmas }\end{array}$ \\
\hline
\end{tabular}


Há, ainda, outros giseigo e gitaigo:

\begin{tabular}{|c|l|}
\hline giseigo & \multicolumn{1}{|c|}{ significado } \\
\hline kon kon & som (latido) emitido pela raposa \\
\hline kyan kyan & choro (ganido) da raposa \\
\hline ton ton & batidas \\
\hline
\end{tabular}

\begin{tabular}{|c|c|}
\hline gitaigo & significado \\
\hline kankan & quente, ardente \\
\hline tsuntsun & pungente \\
\hline
\end{tabular}

Há outros termos grifados, como "kanko" e "shinko", "kanko kanko" e "dokko dokko", que não são onomatopéias; foram conservados, na tradução, para dar ritmo à cantiga que as crianças, na região norte do Japão, costumavam entoar enquanto brincavam e caminhavam pela neve. Vale lembrar que a interpretação das onomatopéias pode sofrer variações de acordo com o contexto.

Para o leitor que não tem o Japonês como língua materna, é bastante difícil compreender a diferença entre onomatopéias semelhantes, ou seja, aquelas aplicadas para um mesmo verbo, como é o caso de "brilhar" e suas variações. Sendo assim, podemos pensar nas onomatopéias como um elemento cultural, sendo difícil imaginá-las como expressões traduzíveis. No entanto, segundo o comentário de SELIGMANN-SILVA (2005:185-186), o recurso de traduzir via não-tradução, para revelar a importância do conceito original, é totalmente legítimo; desde que, evidentemente, venha, como é o caso, sustentado por comentários e glosas. Assim, uma proposta seria elaborar um glossário com o significado de tais onomatopéias.

Quanto ao recurso de se traduzir via não-tradução, podemos destacar ainda algumas passagens de Atravessando a neve, em comparação com os mesmos trechos de uma tradução do conto para o Inglês:

1. “(...) Shiro e Kanko calçaram suas pequenas botas. vukigutsu, e seguiram pela campina, kikku kikku kikku.(...)"

"(...) Shiro and Kanko put on their snow boots made of woven rice straw, and went crunching out into the meadow, kikku kikku kikku.(...)"

2. "(...) - O quê? Mostre-me! Ah, diz aqui: "Solicitamos que, à exceção dos pais e irmãos dos alunos da escola, visitantes com mais de doze anos não compareçam" Aquelas raposas são bem astutas. Então não posso ir, não tem jeito. Bem, se vocês dois estão indo, por que não levam algum mochi? Que tal estes kagami mochi? (...)"

"(...) "What! Show me! Yes, it does say here that with the exception of parents of school pupils, we must politely restrict the attendance of those twelve years of age or older. Those foxes are quite clever. Looks like I can't go. I guess there's no way 
around it. Well, if you two are going to go, why don't you take some rice cakes. How about these large, round ones?" (...)"

Nas duas passagens, os termos em Japonês yukigutsu e kagami mochi foram mantidos na tradução para o Português, e seus significados são apresentados em notas de rodapé. Já no caso da tradução para o Inglês, os significados aparecem no próprio texto, sendo que o kagami mochi da passagem 2 é traduzido diretamente. No entanto, como se trata de uma iguaria típica da época do Ano Novo, a maneira como foi traduzida - "these large, round ones" - faz com que o sentido do termo se perca.

Ainda em referência às onomatopéias, há também a questão da função paronomásica da linguagem: segundo JAKOBSON (1969:150-151), palavras de som semelhante se aproximam quanto ao seu significado. Ainda, segundo Rubens Rodrigues Torres Filho (em SELIGMANN-SILVA (2005:193)), que fez traduções de textos de Novalis, as camadas semânticas não podem ser despregadas da textura sonora (contexto paronomásico do conceito). Acrescentemos também Haroldo de Campos: "em poesia, toda coincidência fonológica é sentida como um parentesco semântico"

Parece que, no caso das onomatopéias do Japonês, via de regra não existe uma relação de similaridade destas com o verbo. De fato, se considerarmos os gitaigo (onomatopéias sensoriais), isso se confirma: tomando-se, por exemplo, o gitaigo "tsun tsun", de "pungente", não existe nenhuma semelhança sonora com o substantivo "akari" ("claridade") que o acompanha. Quanto ao verbo "brilhar" e suas variações: "giragira" "pikapika" "kira kira" "pikari pikari" e "chika chika", já podemos constatar alguma similaridade, pois o verbo " $h$ ikaru" ("brilhar") poderia remeter ao "kira kira" e "giragira" (considerando que neste último o fonema/g/ seria o fonema $/ \mathrm{k} /$ sonorizado). Quanto ao "pikari pikari", existe o verbo "pikari suru", que significa, também, "brilhar"

Temos, ainda, o giseigo "kon kon", que seria a representação do latido da raposa. Pode-se dizer também, no texto, que ele está ligado ao próprio nome da raposa Konzaburo que, além de protagonista do conto, representa um elemento do folclore japonês: como se pode observar no próprio enredo, as raposas apresentam uma carga simbólica negativa, pois são consideradas astutas e enganadoras. No entanto, temos a impressão de que Kenji parece querer desfazer essa imagem, provavelmente levando em consideração que a raposa, enquanto animal, é um elemento pertencente à natureza. E é através das figuras das crianças - menores de doze anos - que isso vem se confirmar, pois estas são capazes de estabelecer conexões com o mundo natural, devido à sua inocência, ao mundo de fantasia que são capazes de vivenciar. Inclusive os campos cobertos de neve poderiam aqui representar uma ponte entre o mundo dos homens - a aldeia - e a natureza - a floresta.

Enfim, estabelecendo-se uma relação entre as onomatopéias e o conto, podese dizer que Kenji faz uso das mesmas para nos aproximar da natureza e das sensações que ela evoca - a brancura de neve, o perfume dos lírios. 
Outro aspecto que nos chama a atenção no conto são os nomes próprios. Em OTTONI (2005:64-65), Bennington (1991) "comenta que o nome próprio deveria garantir 'uma passagem segura entre linguagem e mundo na medida em que deveria indicar um indivíduo concreto, sem ambigüidade, sem ser necessário passar pelos circuitos da significação"' (p.80). E, ao discutir a questão da tradução do nome próprio que pertence sem pertencer à língua (cf.p.122), Bennington afirma:

São necessários nomes próprios a uma língua que não os suporta enquanto tais, mas que no entanto os retém tão ciosamente a ponto de recusar que eles se deixem traduzir para outra língua. Com isso afirma-se, primeiramente, que se esteve errado em falar até então $d a$ língua, ao passo que se está de cara diante de uma multiplicidade de línguas em situação de tradução recíproca: mas o que cada língua guarda de mais próprio e, portanto, de intraduzível, são justamente os nomes próprios que nem mesmo lhe pertencem enquanto tais e que, portanto, devem parecer muito simplesmente dispensar tradução, encontrando-se já em um domínio de universalidade de referência absoluta. $O$ que equivaleria a pretender que o absolutamente intraduzível é absolutamente traduzível, ou sempre já traduzido (p.122).

Ainda, segundo PAZ (1990:18), perder nosso nome é como perder nossa sombra. A ausência de relação entre as coisas e seus nomes é duplamente insuportável: ou o sentido se evapora, ou as coisas se desvanecem.

No Japonês, todos os nomes têm um significado, que varia de acordo com o ideograma (kanji) em que é escrito. De maneira geral, o nome próprio alude a uma qualidade que, diz-se, os pais desejam para os filhos. Em Atravessando a neve, temos, entre outros, Ichiro, Jiro, Saburo e Shiro. Esses quatro nomes representam a ordem de nascimento de meninos em uma família: Ichiro ("ichi" = um) é o nome dado ao primogênito, Jiro ("ji" = dois) é o segundo, Saburo ("sabu" = equivale ao "san" número três - que, juntando-se ao sufixo "ro", sofre sonorização) é o terceiro, e Shiro ( normalmente, acompanha nomes masculinos. Visto que na cultura japonesa é dever do filho mais velho cuidar dos pais na velhice, tal denominação parece ressaltar essa função - o encargo do "filho mais velho" surge inclusive no próprio nome.

Assim, somada à dificuldade em se traduzir o nome pelo significado, não se pode perder de vista o fato de que ele está ligado a um alguém, à sua individualidade, o que então dispensaria a sua tradução.

Concluindo os levantamentos que foram feitos, podemos recorrer a uma proposição de Jacques Derrida, em OTTONI (2005:197): "O que um tradutor nunca tem o direito de fazer é mudar, tocar, retocar o texto original". Ainda que os textos em Japonês tragam em seu corpo alguns aspectos de difícil compreensão aos ocidentais, o que nos remete ao double bind - a necessidade e a impossibilidade - do processo tradutório, há certas modificações que acabam por alterar o sentido do original. 


\section{Bibliografia consultada}

ATÔDA, Toshiko e HOSHINO, Kazuko. Giongo / Gitaigo Tsukaikata Jiten (Dicionário do uso de giongo e gitaigo). 2.ed., Tokyo, Sôtakusha, 1995.

BERNARDINI, Aurora Fornoni. A Tradução e Haroldo de Campos. Revista de Estudos Orientais. São Paulo, DLO/FFLCH/USP, n.5, p.59-64, 2006.

CHANG, Andrew C. Gitaigo / Giongo Bunrui Yôhô Jiten (Dicionário prático de categorias de gitaigo e giongo). 3.ed. Tokyo, Taishûkan, 2000.

HINATA, Shigeo e HIBIYA, Junko. Giongo / Gitaigo - Gaikokujin no tame no Nihongo (Reibun / Mondai shirizu 14) (Giongo / Gitaigo - Japonês para estrangeiros (Série Exemplos / Questões 14). Tokyo, Arakawa Shuppan, 1995.

JAKOBSON, R. Lingüística e poética. In: Lingüística e Comunicação. São Paulo, Cultrix, 1969.

MIYAZAWA, Kenji. Crossing the Snow. Trad.Karen Colligan-Taylor. Tokyo, International Foundation for the Promotivon of Languages and Culture, 2000. (Kenji Miyazawa Picture Book Series - 7)

ONO, Hideichi. Nichiei Gion / Gitaigo Katsuyô Jiten (Dicionário Japonês-Inglês do uso de gion e gitaigo). 5.ed. Tokyo, Hokuseidô, 1994.

OTTONI, Paulo. Tradução manifesta - double bind e acontecimento. São Paulo, Edusp, 2005.

PAZ, Octavio. Traduccion: Literatura y Literalidad. 3.ed. Barcelona, Tusquets Editores, 1990.

SELIGMANN-SILVA, Márcio. O local da diferença - Ensaios sobre memória, arte, literatura e tradução. São Paulo, Editora 34, 2005. 